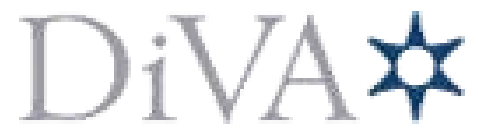

http://kth.diva-portal.org

This is an author produced version of a paper published in Report \#487, Department of Solid Mechanics, Royal Institute of Technology.

This paper has been peer-reviewed but does not include the final publisher proof-corrections or journal pagination.

Citation for the published Report:

Etienne Bonnaud

Issues on Viscoplastic Characterization of Lead-Free Solder for Deep Test Simulations

Report \# 487, Department of Solid Mechanics, Royal Institute of Technology. (Trita HFL 0487) 


\title{
Issues on Viscoplastic Characterization of Lead-Free Solder for Drop Test Simulations
}

\author{
Etienne L. Bonnaud ${ }^{(1,2)}$ \\ ${ }^{(1)}$ Infineon Technologies Sweden AB, Isafjordsgatan 16, SE-164 81 Stockholm Sweden \\ ${ }^{(2)}$ Department of Solid Mechanics, Royal Institute of Technology, SE-100 44 Stockholm Sweden
}

\begin{abstract}
Reliable drop test simulations of electronic packages require reliable material characterization of solder joints. Mechanical properties of lead-free solder were here experimentally investigated for both monotonous and cyclic loading at different strain rates. With regards to the observed complex material behavior, the non-linear mixed hardening Armstrong and Fredrick model combined with the Perzyna viscoplastic law was chosen to fit the experimental data. This model was subsequently implemented into a commercial finite element code and used to simulate drop tests. Actual drop test experiments were conducted in parallel and experimental results were compared to simulations. Prediction discrepancies were analyzed and explanations suggested.
\end{abstract}

\section{Introduction}

A few years ago, two major issues arose within electronics: the global ban of leaded solder and the increasing demand for handheld products to be able to sustain accidental drops. Prior to these two new challenges, extensive work had focused on thoroughly characterizing the thermo-mechanical properties of leaded solder in order to assess thermo-cycling reliability. When subjected to temperature variations, thermal expansion mismatch causes the polymeric printed circuit boards (PCB) to expand and contract more than the ceramic components that are soldered on. The resulting combination of tensile and shear stress in connection with the high homologous temperature (Eutectic Pb-Sn (61.9-38.1)wt\% melts at $183^{\circ} \mathrm{C}$ and thermocycling experiments are typically conducted between $-40^{\circ} \mathrm{C}$ and $125^{\circ} \mathrm{C}$ ) lead to large plastic strains eventually causing mechanical and electronic failure.

When focus shifted from leaded to lead-free solder, it seemed reasonable to keep on using the previously developed constitutive models but with new sets of material parameters, see [1] for a gathering of material parameters both for leaded and lead-free solders.

Among various candidates, SnAgCu solders early emerged as suitable alternatives partly because of their relatively low cost and relatively low melting temperatures ( $\mathrm{Sn}$-Ag-Cu (96.13.4-0.5)wt\%, for example, melts at $217^{\circ} \mathrm{C}$ ). All over the world a vast amount of experiments were conducted on different weight compositions, at different temperatures and at different strain rates. This approach was successful and Finite Element Simulations with lead-free solder joints were soon to give reliable results.

Publications dealing with thermo-cycling reliability are numerous and can be divided into two groups depending on whether time independent and time dependent plasticity are modeled separately or not. In the first approach, strain hardening plasticity and creep are assumed to be completely uncoupled; an advantage is that their contribution to plastic strain over thermocycles can be compared and analyzed [2]. More advanced models feature two creep regimes 
in order to take into account the different mechanisms for dislocations to pass by obstacles [3]. For small stresses, atoms and vacancies diffusion is the only way for dislocations to climb over obstacles; this process is strongly temperature dependent and intrinsically slow. For higher stresses, particle shearing (small obstacles) and Orowan bowing (large obstacles) take over; these processes are considerably faster. This difference in velocities gives rise to two distinct creep strain rates.

Even though it has been proven that such a decoupling between strain hardening plasticity and creep is necessary when the Perzyna model is used over a large range of temperatures [4], the trend has mainly been to build in hardening in the creep function. Among the models following this second approach, the most widely-used is certainly the so called Anand's model $[5,6]$. In this creep model based on isotropic hardening, the hardening parameter entering the creep rate function takes into account strain hardening and dynamic recovery (but neglects static recovery). Originally developed to describe hot working of metals (steel and aluminum), this model is naturally appropriate to describe the behavior of solder joints during thermo-cycling during which high homologous temperatures prevail. Together with a low cycle fatigue criterion (a Coffin-Manson law) based on the evolution of plastic strains during a stabilized cycle, the Anand's model has been the ground for reliability assessment in electronics and is usually referred to as the Darveaux method [7]. Nine material parameters need to be determined by combined experiments and curve-fitting.

As thermo-cyclic loading consists of a succession of combined normal and shear stresses both changing sign in each cycle, it seems natural to investigate solder material cyclic behavior. Experiments show a rapid saturation of isotropic hardening and a strong Bauschinger effect indicating both a fairly constant dislocation density (where dynamic recovery balances the generation of new dislocations) and an effective dislocation remobilization at reverse flow [8]. Out of many non-linear kinematic hardening laws the Armstrong and Fredrick model, due to its simplicity and convenience, has been widely used and the starting point for numerous models of increasing complexity [9]. Purely kinematic models combined to a temperature dependent creep law emerged [8] and were even used with a failure criterion [10] similar to the one presented by Darveaux [7]. Other models combined the Armstrong and Fredrick model with a creep law depending on both temperature and damage parameters [11]: with increasing damage, back stress reduces which in turn reduces the overall stress allowing to model softening of the material. Damage parameters are calibrated by measuring the changes of Young's modulus and Poisson's ratio. More advanced models feature mixed hardening (isotropic hardening and the Armstrong and Fredrick kinematic hardening) used with a damage function [12].

Two advanced models originally developed for steel are of interest for solder joint modeling. First, the Chaboche model improves the Armstrong and Fredrick model by offering a better estimation of ratcheting and the capability of modeling isotropic hardening stabilization for different strain ranges $[13,14]$. To achieve these results a superposition of several kinematic hardening rules is used as well as an additional internal variable keeping track of the largest cyclic strain amplitude. Secondly, the model presented in [15] features an additional term in the isotropic hardening function. The first term as usual stands for hardening (non-linear hardening taking into account dynamic recovery) during monotonous loading but the second term, only active at reversing events, allows the material to soften before rehardening. 
When it comes to drop test, in order to allow comparison between experiments, the Joint Electron Devices Engineering Council (JEDEC) came out with a standard [16] describing drop test conditions (test board properties, test procedure, failure analysis, etc.). Early drop test experiments focused on quasi-static cyclic bending of test boards; in [17] for example failure results were compared to simulations where the plastic strain was monitored and inserted in a Coffin-Manson relation. Analytical and numerical studies used dynamics to describe the behavior of the test board immediately after impact. Design guidelines (PCB thickness, solder joint height, etc.) emerged [18,19] and an analytical proof based on beam dynamics of the predominance of bending on inertia effects to drive failure was given [20]. Analytical studies also investigated the influence of the impact pulse on the PCB bending and on the stress in the solder joints [21]. Mixed experimental and numerical studies tried to correlate crack propagation with simulations [22]: monitoring electrical resistance of daisychain components allows to follow crack propagation and cross sectioning of failed components gives an indication of failure mode. Experimental results were compared to the maximum peeling stress and to both the maximum peeling stress and the effective plastic strain [23]. Bilinear kinematic hardening was also occasionally used: in [24], the effective plastic strain enters a Coffin-Manson law to evaluate life expectation as in [17].

In drop test simulations solder joint material is nearly always modeled as linear elastic. Nevertheless, due to the high elastic stress levels predicted, use of more advanced material models is necessary. Again it seems tempting to focus on material models previously used for temperature cycling and as a matter of fact temperature cycling and drop test have in common two essential features: time dependency and cyclic bending response. Succession of tensile and compressive stresses is caused in temperature cycling by thermal expansion mismatch and in drop test by upwards and downwards bending of the PCB. Time dependency is embodied in temperature cycling by the slow development of plastic strains at slowly varying loads and in drop test by the dependency of stress levels on the strain rate shifting the strainstress curves towards higher stresses when strain rate increases. The first effect is generally referred to as creep and the second as viscoplasticity. Despite being described by similar equations creep and viscoplasticity are fundamentally different phenomena and should not be taken for one another. Confusion in the literature are unfortunately frequent. In drop test where events usually last a few milliseconds and where strain rates approaches 200/s, viscoplasticity models are clearly to be preferred over creep models; use of temperature cycling models for drop test is therefore not straight-forward.

Here mechanical properties of solder joint material were investigated. SnAgCuNi test specimens were subjected to both monotonous and cyclic loading at different strain rates. Results were used to estimate material parameters of two viscoplastic models: the first one featuring non-linear isotropic hardening and the second one (the Armstrong and Fredrick model) featuring non-linear mixed hardening. The latter model is not a regular material model in LSDyna [25] and was implemented as a user-defined subroutine. In parallel, drop test experiments on electronic components soldered on a PCB were carried out. Failure locations were monitored and cross sections at failure locations were analyzed in a scanning electron microscope (SEM). Drop test simulations were run for the Armstrong and Fredrick model and the results compared to drop test experiments. Finally the prediction capability of the method presented here is discussed and possible improvements suggested. 


\section{Material characterization}

\subsection{Practical aspects}

The mechanical properties of solder material are known to be highly temperature- and ratedependent. Temperature effects were not taken into account here and all experiments were conducted at room temperature. In order to have the same microstructure, test specimens for monotonous or cyclic loading were manufactured from the same cast bar and to avoid unnecessary scatter in the results, experiments were conducted the same day on the same equipment with the same settings. The shape and size of the test specimens were modified from what usually prevails for steel. To prevent bending during compression, the effective length of the specimens was shortened and to prevent slip in the test fixture (due to creep), the end diameter of the specimens was increased and a lid added to the fixture, see Fig. 1. Experiments were conducted in displacement control.

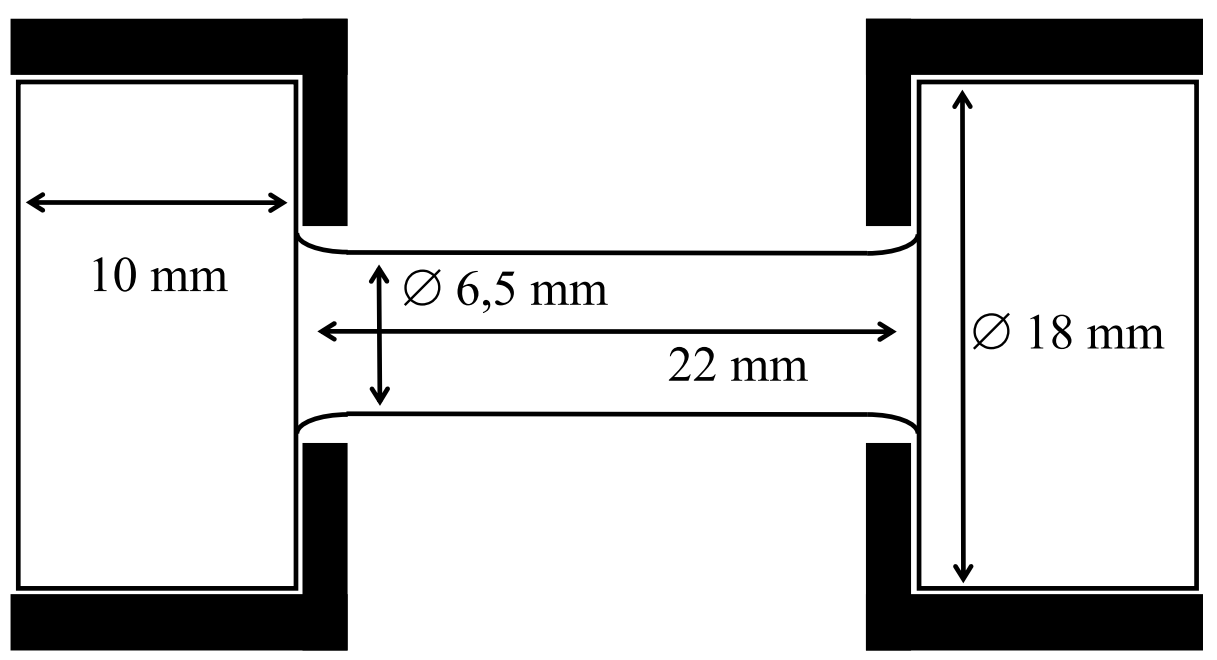

Figure 1: Test specimen dimensions; effective length was shortened to $22 \mathrm{~mm}$ and end diameters were increased to $18 \mathrm{~mm}$. Black areas show the shape of the fixture designed to prevent the specimen from sliding out.

\subsection{Monotonous tensile loading}

$\mathrm{SnAgCuNi}$ samples were subjected to tensile loading at three different strain rates: $0.2 / \mathrm{s}, 1 / \mathrm{s}$ and 5/s. Necking occurs at strains around 0.1 and failure at strains between 0.35 and 0.45 , see Fig. 2. Raw data was converted from engineering strain and stress to true strain and stress but no correction for necking (Bridgman correction) was carried out. Strain rate dependency is obvious: curve maxima are 55, 65 and $75 \mathrm{MPa}$, respectively. Similar experiments conducted on $\mathrm{SnAgCu}$ samples gave similar results except for the maximum values being instead: 65,75 and $85 \mathrm{MPa}$. In other words $\mathrm{SnAgCuNi}$ was found to be weaker than $\mathrm{SnAgCu}$. 


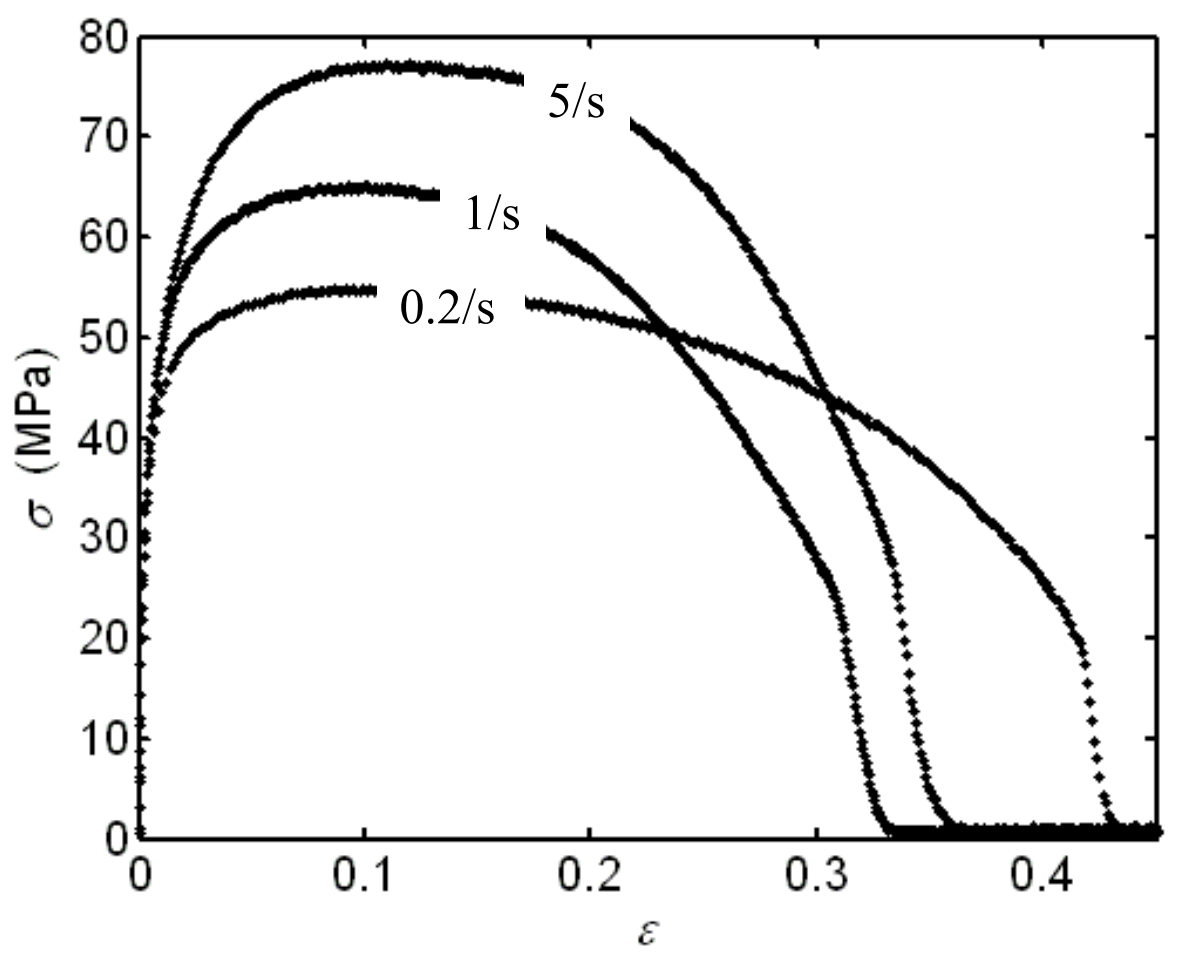

Figure 2: Experimental true stress vs. true strain for monotonous loading up to complete failure at three strain rates $(0.2 / \mathrm{s}, 1 / \mathrm{s}, 5 / \mathrm{s})$. Necking sets in around $\varepsilon=0.1$.

\subsection{Cyclic tensile and compressive loading}

Cyclic testing was carried out for strains between +0.01 and -0.01 at two different strain rates: $0.04 / \mathrm{s}(1 \mathrm{~Hz})$ and $0.2 / \mathrm{s}(5 \mathrm{~Hz})$. Strain-stress results for $5 \mathrm{~Hz}$ are presented in Fig. 3. Due to limitations in the hydraulic equipment, strain rates were bounded to these rather low values in order for the time displacement response to retain its triangular shape (higher strain rates give a more sinus-shaped displacement curve). Applied strains being here limited to an amplitude of 0.01 , no conversion to true strain and stress was needed. Stresses obtained at $0.2 / \mathrm{s}$ for monotonous and cyclic loadings for strains between 0 and 0.01 were checked to be in full agreement as they should. Cyclic mechanical behavior exhibits two distinct features: hardening within each cycle and hardening followed by softening between cycles. At $0.2 / \mathrm{s}$ maximal tensile stress values increase from $41 \mathrm{MPa}$ to $44 \mathrm{MPa}$ between the first and the second cycle but decrease by $0.1 \mathrm{MPa}$ between each of all the subsequent cycles. (At $0.04 / \mathrm{s}$ these values are $38.5 \mathrm{MPa}, 40 \mathrm{MPa}$ and $0.08 \mathrm{MPa}$, respectively.) In order to further investigate this softening effect, a specimen was subjected to three sets of 20 cycles obtained at $0.2 / \mathrm{s} \mathrm{separated}$ by a one minute pause, see Fig. 4 . Envelopes of the three sets where the first cycle of each set was removed show a stress decrease within each set (A to B, C to D and E to F) and a stress increase between the sets ( $B$ to $C$ and D to E). Reasons for this behavior are probably temperature and damage related. Almost all plastic deformation energy being converted into heat, test sample temperature increases within each set causing the material to soften (and subsequent cooling down makes it reharden). Note that dynamic recovery due to dislocation annihilation or alteration of the microstructure in form of microcracks could explain softening within sets but not re-hardening between sets. Static recovery due to 
microstructure restoration, see [5], can not be invoked here either as it would have the opposite effect namely softening between sets. This softening mechanism being of rather small amplitude, it will not be considered further below.

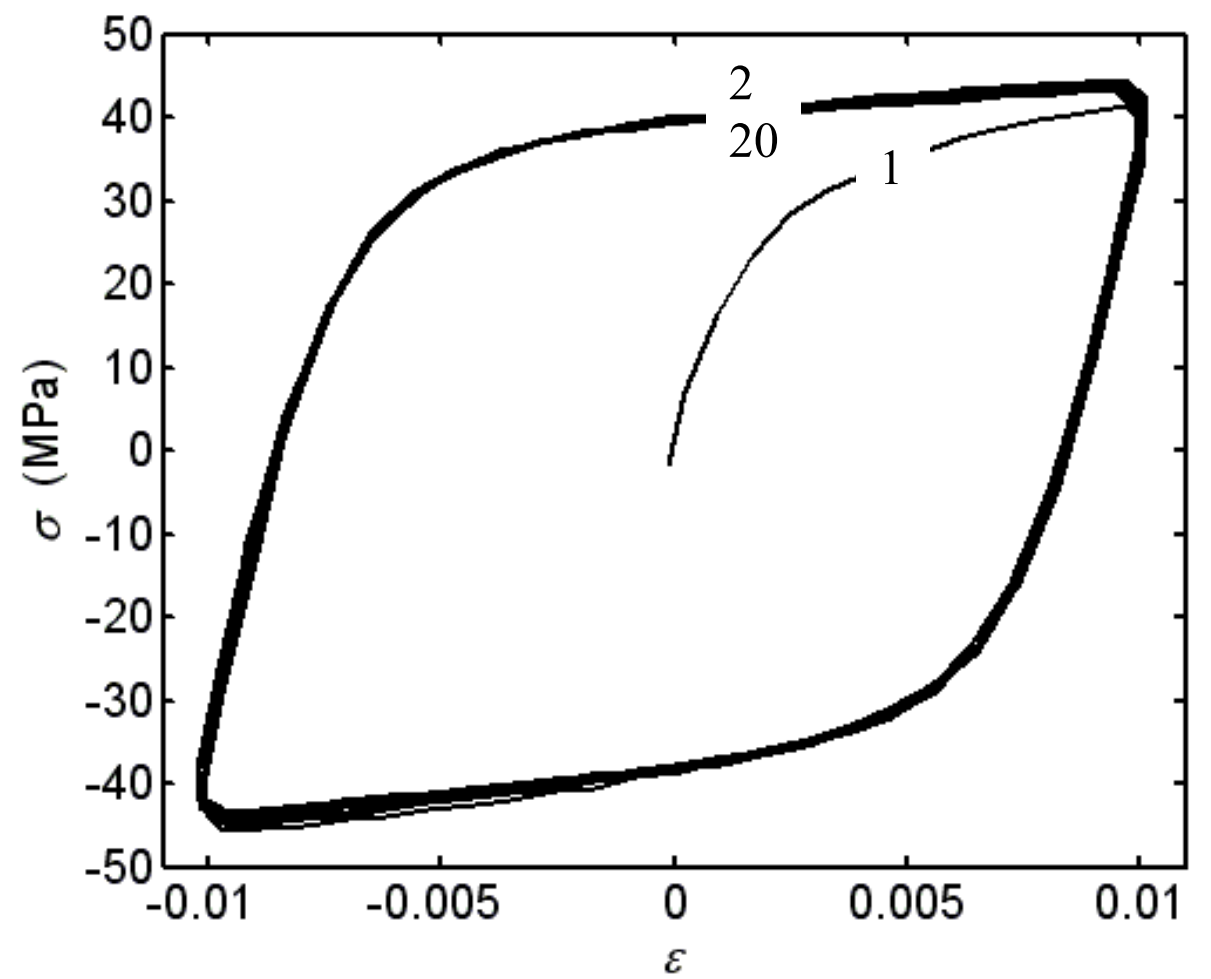

Figure 3: Experimental engineering stress vs. engineering strain for cyclic loading (20 cycles) at $0.2 / \mathrm{s}$; cyclic hardening between cycle 1 and 2 followed by cyclic softening between subsequent cycles.

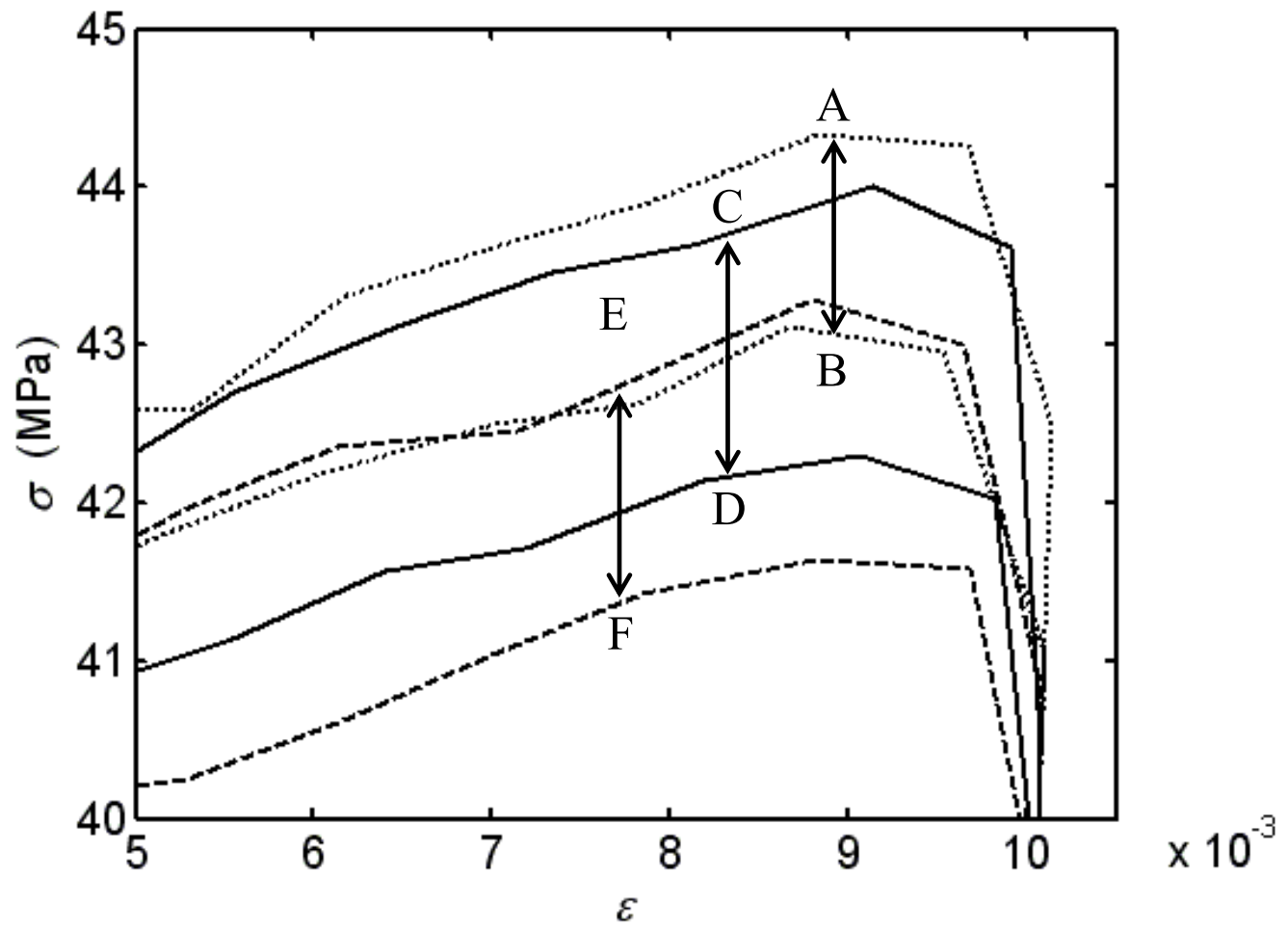

Figure 4: Experimental envelopes ( $2^{\text {nd }}$ and $20^{\text {th }}$ cycles) of each of the 3 sets of 20 cycles at $0.2 / \mathrm{s}$. A-B: cycles 2-20; C-D: cycles 22-40; E-F: cycles 42-60. Resting time between sets: 1 min. 


\section{Material model and estimation of model parameters}

\subsection{Monotonous loading}

Curve fitting was carried out on data for strains up to 0.1 (where necking sets in) for the three strain rates $(0.2 / \mathrm{s}, 1 / \mathrm{s}$ and $5 / \mathrm{s})$ simultaneously. Apparent or seeming initial yield stress was estimated directly as the point where the three curves go apart and apparent or seeming elastic modulus as the slope between the origin and this point. Among various creep and hardening alternatives, non-linear isotropic hardening combined with the Perzyna viscoplastic model gave the best curve fitting, see Fig. 5 .

$$
\begin{aligned}
& \left|\dot{\varepsilon}_{\mathrm{p}}\right|=\dot{\varepsilon}_{0}\left\langle\frac{|\sigma|}{\sigma_{y}}-1\right\rangle^{n} \\
& \sigma_{y}=\sigma_{y_{0}}+\sigma_{\infty}\left[1-\exp \left(-k\left|\varepsilon_{\mathrm{p}}\right|\right)\right]
\end{aligned}
$$

The McCauley bracket entering Eq. 1 is defined by: $\langle A\rangle=A$ if $A \geq 0$ and 0 otherwise. The entire set of material parameters consists of two elastic $\{E, v\}$, two viscoplastic $\left\{\dot{\varepsilon}_{0}, n\right\}$ and three isotropic hardening parameters $\left\{\sigma_{y_{0}}, \sigma_{\infty}, k\right\}$, all listed in Tables I and II.

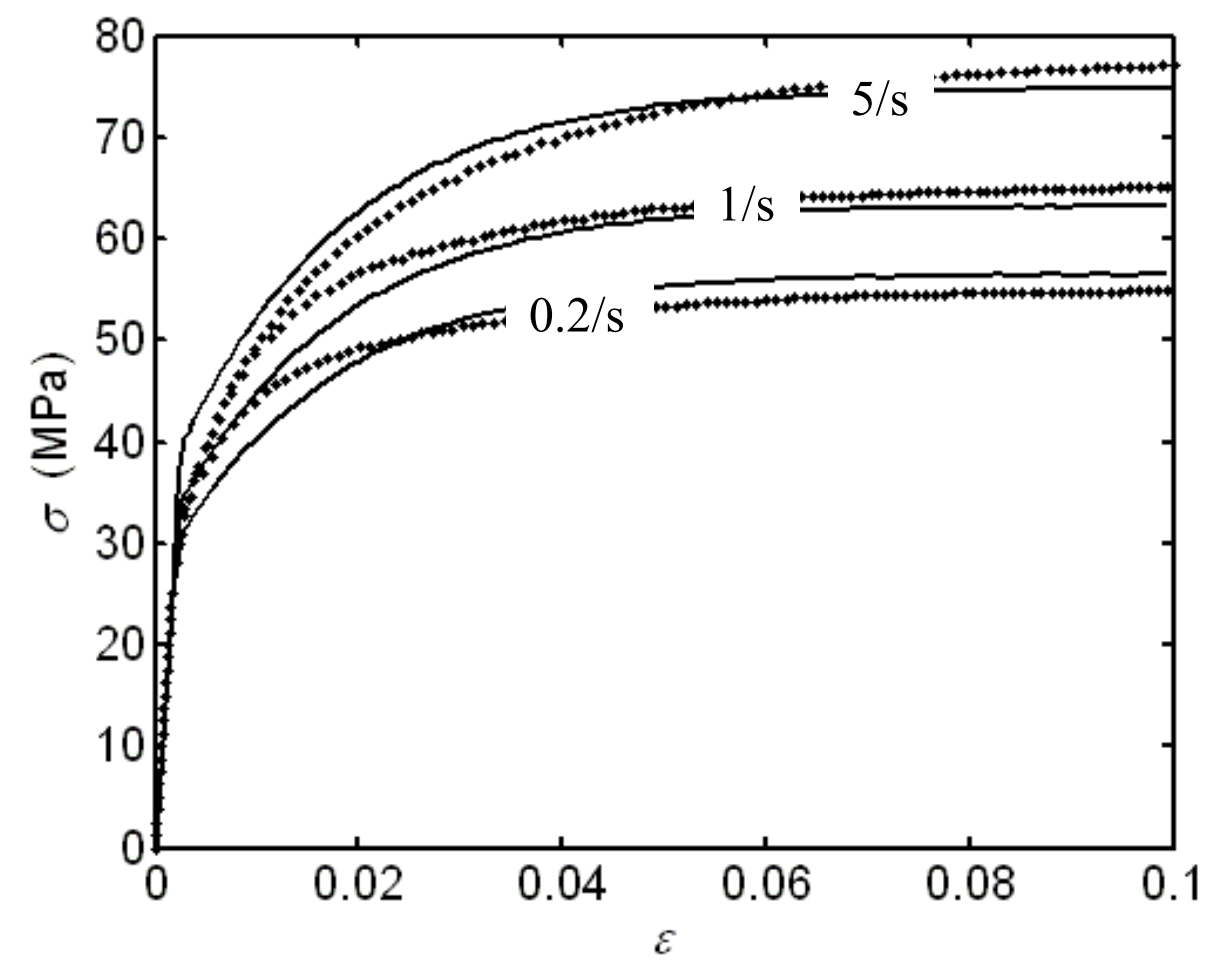

Figure 5: True stress vs. true strain for monotonous loading up to necking at three strain rates $(0.2 / \mathrm{s}, 1 / \mathrm{s}, 5 / \mathrm{s})$ : experiment (dotted lines) and model prediction (solid lines).

Table I: Elastic properties and density

\begin{tabular}{|c|c|c|}
\hline$E[\mathrm{MPa}]$ & $v[-]$ & Density $\left[\mathrm{kg} / \mathrm{m}^{3}\right]$ \\
\hline 20000 & 0.36 & 7500 \\
\hline
\end{tabular}


Table II: Viscoplastic and hardening properties (monotonous loading)

\begin{tabular}{|c|c|c|c|c|}
\hline$\dot{\varepsilon}_{0}\left[\mathrm{~s}^{-1}\right]$ & $n[-]$ & $k[-]$ & $\sigma_{y_{0}}[\mathrm{MPa}]$ & $\sigma_{\infty}[\mathrm{MPa}]$ \\
\hline 24 & 3 & 66 & 25 & 22 \\
\hline
\end{tabular}

\subsection{Cyclic loading}

In order to be able to capture the non-linear mixed hardening observed during cyclic loading, the Armstrong and Fredrick model was chosen, again in combination with the Perzyna viscoplastic model.

$$
\begin{aligned}
& \left|\dot{\varepsilon}_{\mathrm{p}}\right|=\dot{\varepsilon}_{0}\left\langle\frac{|\sigma-\alpha|}{\sigma_{y_{0}}+K}-1\right\rangle^{n} \\
& \dot{\alpha}=(1-m) h\left(\dot{\varepsilon}_{\mathrm{p}}-\frac{\alpha}{\alpha_{\infty}}\left|\dot{\varepsilon}_{\mathrm{p}}\right|\right) \\
& \dot{K}=m h\left(1-\frac{K}{K_{\infty}}\right)\left|\dot{\varepsilon}_{\mathrm{p}}\right|
\end{aligned}
$$

Note that Eq. 4 is only valid for uniaxial loading; in multiaxial loading the backstress $\alpha$ is tensorial and a factor 2/3 enters the equation [9]. As seen from Eqs (4-5) four additional parameters $\left\{m, h, \alpha_{\infty}, K_{\infty}\right\}$ are necessary to describe mixed isotropic and kinematic hardening. Nevertheless this mixed hardening model and the isotropic hardening model described in the previous section should give the same results for monotonous loading irrespective of the value of $m$. Integrating Eqs (4-5) and requiring equivalence between Eq. 1 and Eq. 3 in the rate independent limit $\left(\dot{\varepsilon}_{\mathrm{p}} \rightarrow 0\right)$ gives two additional equations.

$$
\begin{aligned}
& \alpha_{\infty}+K_{\infty}=\sigma_{\infty} \\
& (1-m) \frac{h}{\alpha_{\infty}}=m \frac{h}{K_{\infty}}=k
\end{aligned}
$$

These equations can be rearranged so that the hardening parameters $h, \alpha_{\infty}$ and $K_{\infty}$ solely depend on previously determined parameters and on the hardening parameter $m$.

$$
\begin{aligned}
& h=k \sigma_{\infty} \\
& \alpha_{\infty}=(1-m) \sigma_{\infty} \\
& K_{\infty}=m \sigma_{\infty}
\end{aligned}
$$

Consequently only $m$ needs to be determined and this can easily be done by direct estimation of the reverse plastic deformation onset in Fig. 3. The entire parameter list is given in Table III and, as seen in Fig. 6, agreement between predictions and experiments is satisfactory. As usual with symmetric cyclic loading, stresses stabilize after a few cycles. Note that in contrast to the classical Melan-Prager evolution law, cyclic stabilization of the kinematic part of the Armstrong and Fredrick model is not instantaneous and takes a few cycles. 


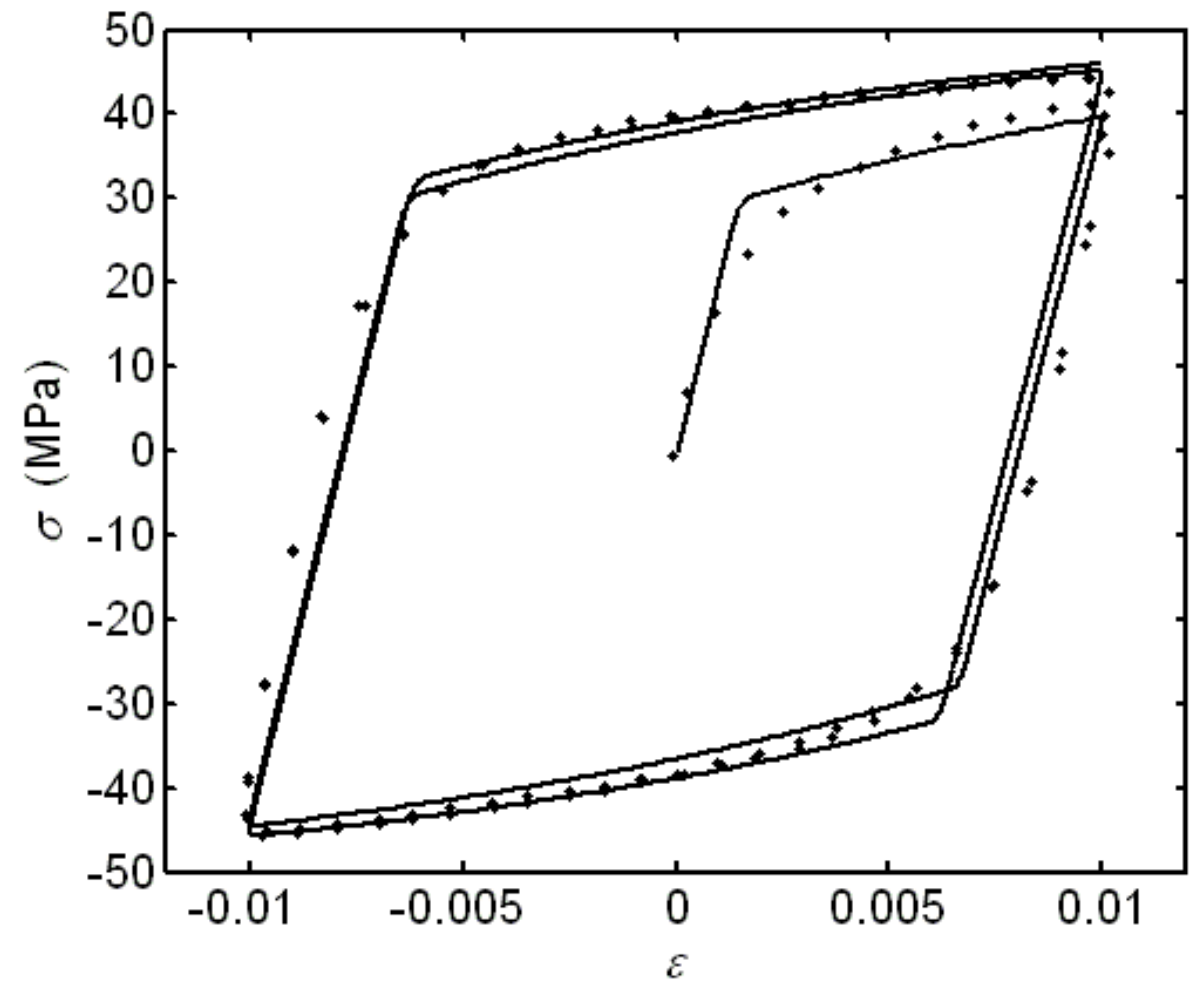

Figure 6: Engineering stress vs. engineering strain for cyclic loading ( 3 first cycles) at strain $0.2 / \mathrm{s}$ : experiment (dotted lines) and model prediction (solid lines).

Table III: Hardening properties (cyclic loading)

\begin{tabular}{|c|c|c|c|}
\hline$m[-]$ & $h[\mathrm{MPa}]$ & $\alpha_{\infty}[\mathrm{MPa}]$ & $K_{\infty}[\mathrm{MPa}]$ \\
\hline 0.35 & 1452 & 14.3 & 7.7 \\
\hline
\end{tabular}

\section{Drop test experiments}

\subsection{Set-up}

Test components chosen for drop test experiments were so called LFBGA: Low-profile Finepitch Ball Grid Array. Overall dimensions were $13 \mathrm{~mm}$ by $13 \mathrm{~mm}$, standoff: $0.15 \mathrm{~mm}$, solder joint ball diameter: $0.3 \mathrm{~mm}$ and pitch: $0.5 \mathrm{~mm}$. Connections consisted of a 9 by 9 array at the center and of 3 outer rows, see layout in Fig. 7. A total of 15 components were soldered on each PCB according to the JEDEC standard [16], see Fig. 8. Test boards, $77 \mathrm{~mm}$ by $132 \mathrm{~mm}$, were attached by four corner screws to a fixture gliding along two vertical rods. Drop height was adjusted to $0.7 \mathrm{~m}$ (corresponding to a theoretical speed of $3.7 \mathrm{~m} / \mathrm{s}$ ) so the peak acceleration at the middle of the PCB was $1500 \mathrm{~g}$. In order to record electrical failure, the 345 connections of each component were daisy-chained and connected to a high frequency failure detection device. Finally a high-speed camera recorded the overall displacement of the PCB.

\subsection{Results}

Both solder materials, $\mathrm{SnAgCu}$ and $\mathrm{SnAgCuNi}$, were tested a repeated number of times and the results showed a distinct trend. Components located at the middle of the long edges failed 
first followed by the component at the center and components at the corners of the PCB. The components that failed last were the ones located at the middle of the short edges and their closest inwards neighbors. Due to symmetry, only 6 of the 15 locations need to be studied and after numbering according to Fig. 8, the failure sequence reads: $3-2-6-1-5-4$. This result can be used as a design guideline for practical applications: sensitive components should be placed at the middle of short edges (position 4); more hardwearing components should instead be placed at the middle of long edges (position 3). Comparison between the two soldering alloys was clearly in favor of $\mathrm{SnAgCuNi}$. The first failure with $\mathrm{SnAgCu}$ could come as early as at the $2^{\text {nd }}$ drop whereas first failure with $\mathrm{SnAgCuNi}$ usually came around the $40^{\text {th }}$ drop.

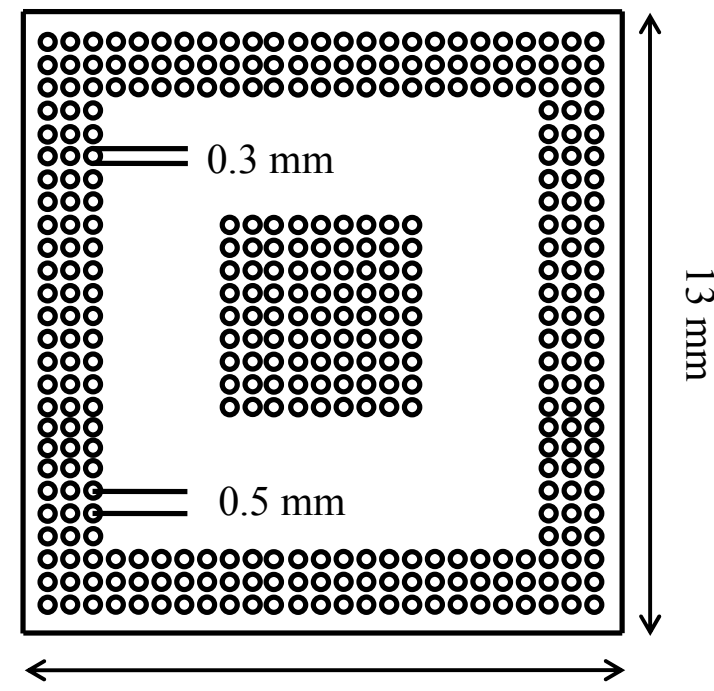

$13 \mathrm{~mm}$

Figure 7: Layout of the test component BGA 345. Solder joint ball diameter is $0.3 \mathrm{~mm}$ and pitch is $0.5 \mathrm{~mm}$. Plastic strains are monitored at bottom left pad of each of the 6 components.

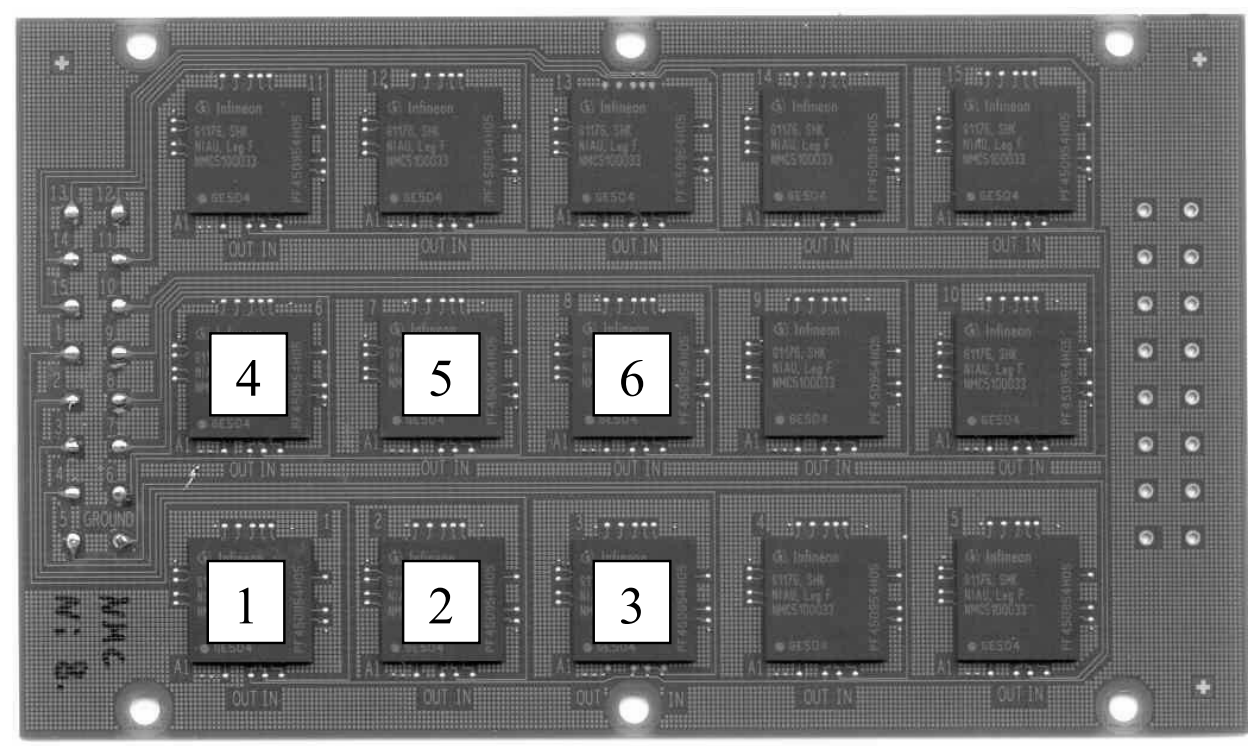

Figure 8: Jedec drop test card; note that only the four corner holes are used for mounting on the drop test fixture. Due to symmetry, only 6 of the 15 component locations need to be monitored; numbering is used in Figs 10-12. 


\section{Drop test simulations}

\subsection{FEM implementation}

The Armstrong and Fredrick model combined to the Perzyna viscoplastic model was implemented as a user-defined material subroutine in LS-Dyna. In order to increase numerical stability and to avoid computation of "contact stresses" when crossing the yield surface, a fully implicit scheme was chosen. The implementation is based on the "radial return" formulation even though the "recall term" in the Armstrong and Fredrick model causes the return onto the yield surface not to be radial any more, see Appendix for details.

\subsection{Model}

The model shown in Fig. 9 was built with solid elements in Ansys [26], run in LS-Dyna and analyzed in the LS-Dyna postprocessor LS-Prepost.

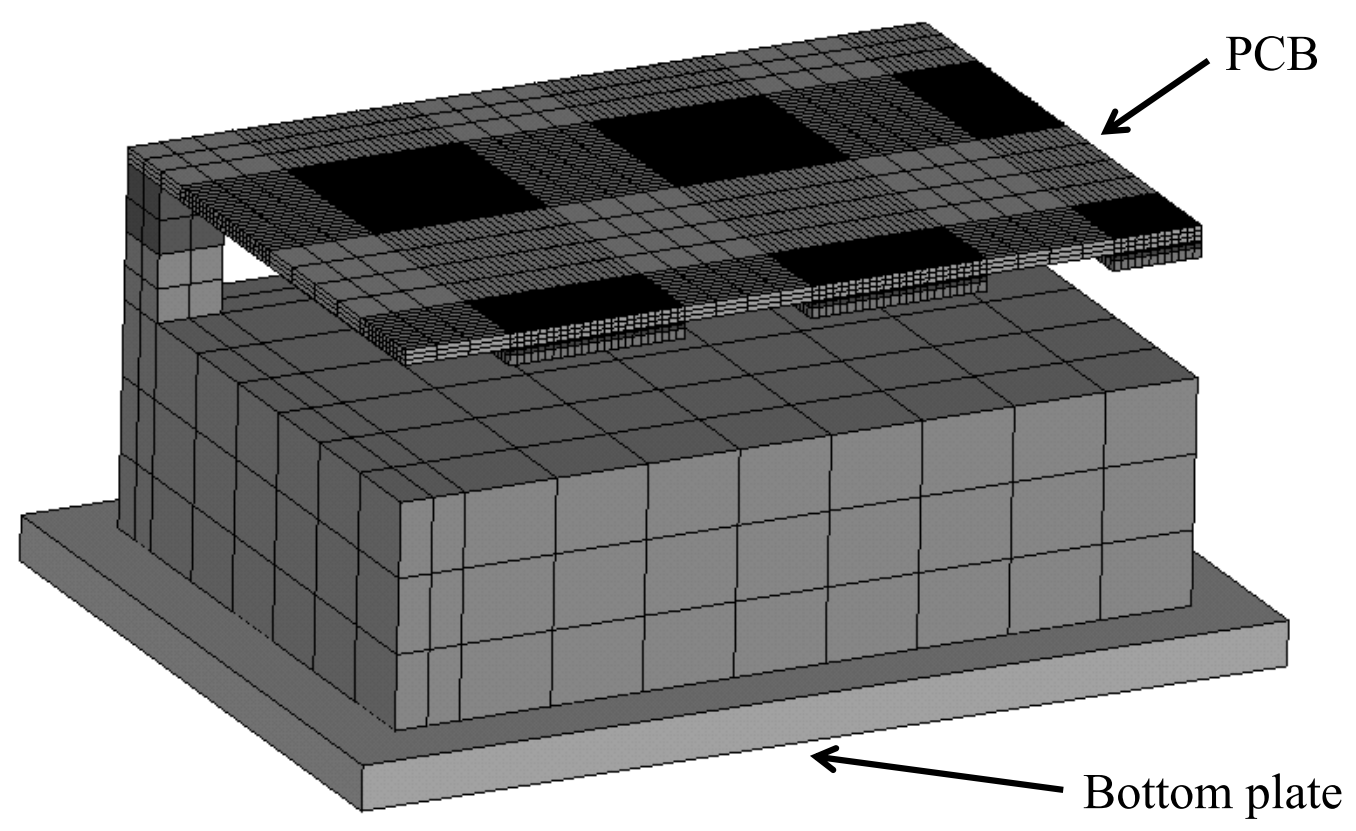

Figure 9: Quarter FEM model for drop test simulations. According to standards, components are placed underneath the PCB. The bottom plate consists of a single rigid element.

All materials were chosen to be linear elastic except for the solder joints material, which was assigned the Armstrong and Fredrick model through the previously described user-defined subroutine. Round pads and screws were modeled as squares of corresponding area in order to allow mapped brick meshing. The total number of elements was therefore kept low and the smallest element size kept as high as possible, which is a prerequisite for reasonable time stepping in a dynamic analysis. Reduced integration and hourglass control were preferred to fully integrated elements which are more time consuming and behave poorly when their aspect ratio is far from unity. Finally the PCB bending amplitude $(5.4 \mathrm{~mm})$ and frequency $(200 \mathrm{~Hz})$ measured by high-speed camera during drop test experiments were used to calibrate the FE-model mechanical properties. In that way the dynamic response of the numerical simulations was brought close to the dynamic response observed in the experiments. 


\subsection{Results}

At $200 \mathrm{~Hz}$, the time necessary for the card to bend downwards and upwards one single time is $5 \mathrm{~ms}$. Total simulation time was therefore set to $5 \mathrm{~ms}$ which is also the duration simulation results shown in Figs 10-12 span over. At each of the six locations defined in Fig. 8, the left bottom node of the solder joint located at the left bottom corner of the component was selected for data recording. Figure 10 shows the displacements relative to the fixture this is to say after removal of the fixture rigid body motion.

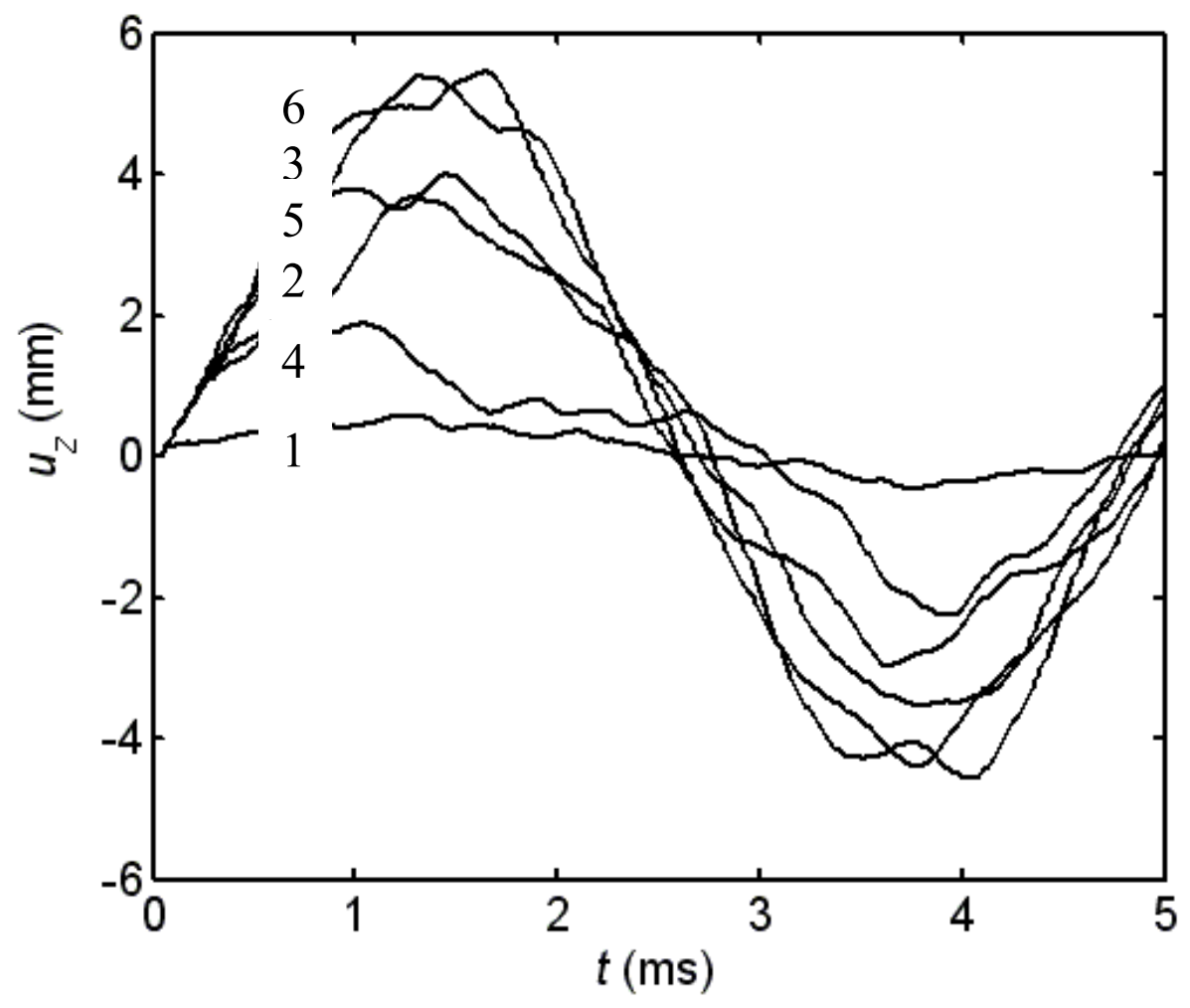

Figure 10: FEM simulations of displacements in solder joints (locations 1 to 6 are defined in Fig. 8).

As expected components further away from the fixation screw at the corner experience larger displacements: in descending order the ranking reads: $6-3-5-2-4-1$. The first three natural frequencies calculated by modal analysis are $151 \mathrm{~Hz}, 436 \mathrm{~Hz}$ and $693 \mathrm{~Hz}$. Close look at the displacement animation show the predominance of the first bending mode and only little influence of the higher order modes. The reason why the frequency measured experimentally was $200 \mathrm{~Hz}$ and not $151 \mathrm{~Hz}$ lies in the rather large out-of-plane experimental displacements. Modal analysis is based on the assumption of small displacements whereas finite displacements encountered in the experiments give rise to an additional membrane stress which results in an additional stiffness and therefore a higher frequency. Figure 11 shows the development of effective plastic strains and the ranking in descending order reads 1 - 6 - 4 - 2 - 3 - 5. Figure 12 shows the stress distributions at locations 3 (where failure occurs first during experiments) and locations 6 (where the maximum stress is the highest in simulations). 


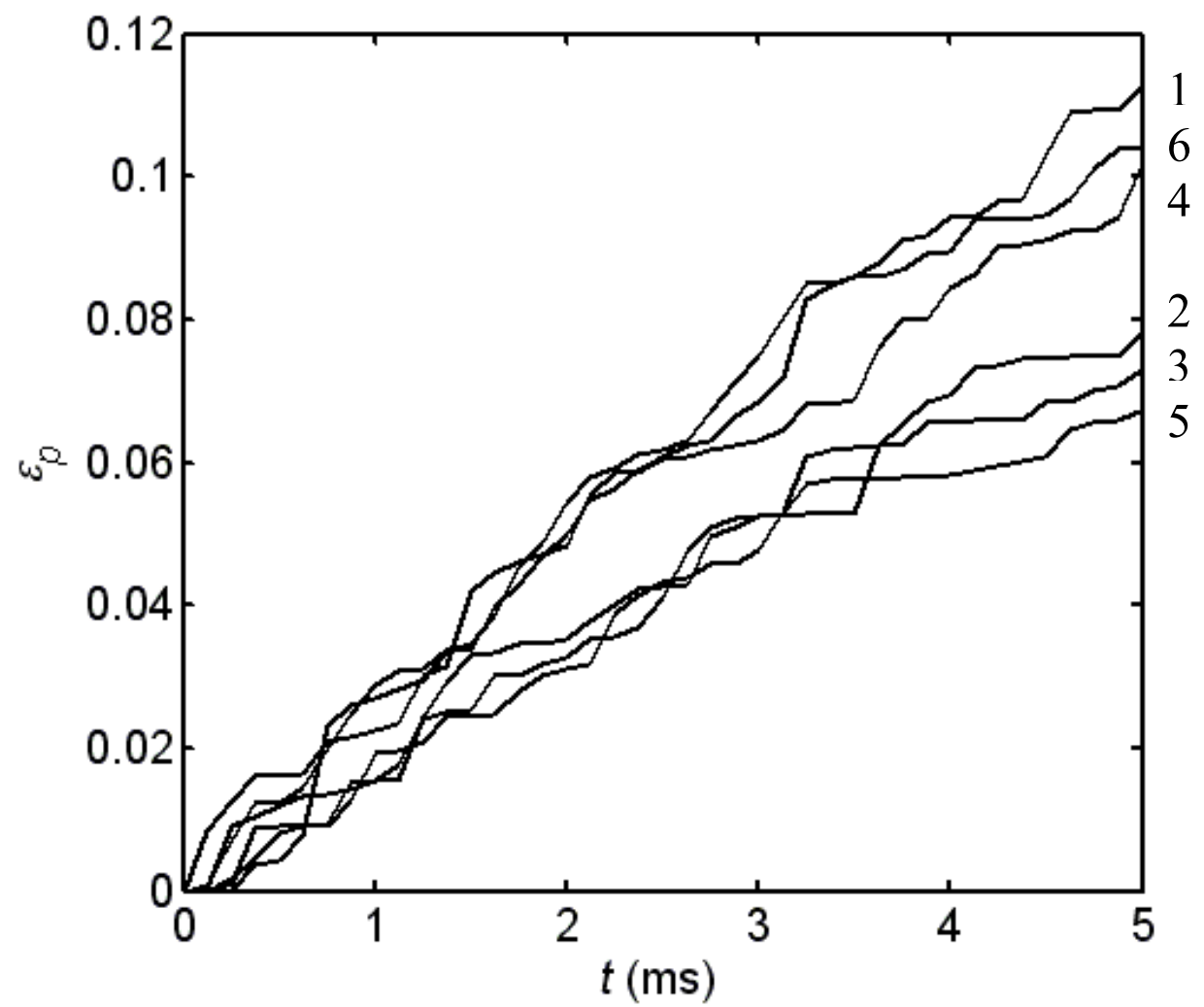

Figure 11: Armstrong and Fredrik model: FEM simulations of effective plastic strains in solder joints (locations 1 to 6 are defined in Fig. 8).

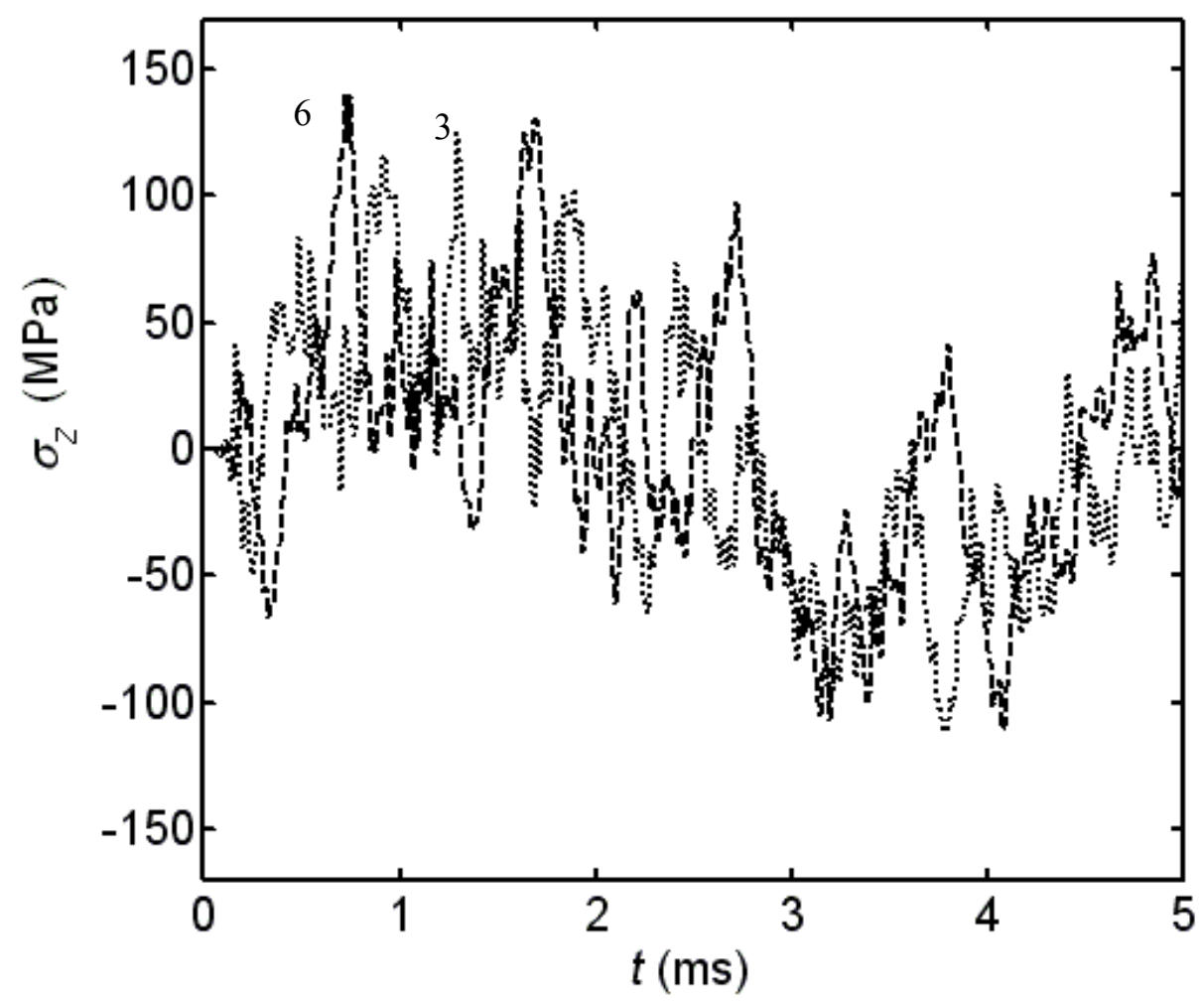

Figure 12: Armstrong and Fredrick model: comparison of the peeling stress $\sigma_{z}$ at location 3 (dotted line) where failure occurs in practice and location 6 (dashed line) for which the simulated stress is maximum.

The maximum peeling stress values ranking in descending order is: $6-2-1-3-4-5$. Peeling stresses are hard to compare to each other because of the many high frequency events. 
Note that maximum peeling stress and plastic strain do not exactly give the same information: maximum peeling stresses correspond to short time events whereas plastic strains can be more or less seen as a time integration of the whole stress distributions. High maximum peeling stress contributes to high plastic strain but the highest maximum peeling stress does not necessary go in pair with the highest plastic strain.

\section{Discussion}

Comparison between experiments and simulations show that the experimental failure sequence and the values of displacements, plastic strains and peeling stresses reported in the previous sections are not in agreement.

Stresses experienced by solder joints are caused by two distinct phenomena: PCB bending and inertia effects. With the ceramic components being a lot stiffer than the PCB they are soldered on, bending of the PCB results in both shear and normal stresses in the solder interconnections. At the same time rapid deceleration of the PCB causes rapid and substantial tensile stress in the solder joints simply due to inertia of the soldered components. Previous analytical analysis based on a freely supported beam showed that bending effects are supposedly two orders of magnitude stronger than inertia effects, see [20]. Free support (for beams) and constrained corners (for plates) are nevertheless rather different boundary conditions and inertia effects can here very well explain the difference between displacement and stress rankings.

As satisfactory as the isotropic and mixed hardening models fit experiments, at least two problems need to be addressed. As previously mentioned Young's modulus and the yield stress were only seeming values as they were estimated to fit this particular series of experiments. A more rigorous method would let $\sigma_{y_{0}}$ depend on the strain rate and would make use of ultrasonic testing to evaluate Young's modulus, see [12]. Moreover the strain rate range $(0.2 / \mathrm{s}-5 / \mathrm{s})$ used for material characterization is way below the actual strain rates prevailing in experiments $(\sim 200 / \mathrm{s})$ and it is well known that using a model for values far outside the ones used for curve fitting is in general not reliable. Going back to monotonous loading (Fig. 5) and noting that $\log (\mathrm{d} \varepsilon / \mathrm{d} t)$ with $\mathrm{d} \varepsilon / \mathrm{d} t=\left[\begin{array}{lll}0.2 & 1 & 5\end{array}\right]$ vs. $\log \left(\sigma_{\max }\right)$ with $\sigma_{\max }=\left[\begin{array}{ll}55 & 65\end{array}\right.$ 77] is a straight line, $\sigma_{\max }$ for $200 / \mathrm{s}$ can be extrapolated to $115 \mathrm{MPa}$. Multiplying the experimental values for the $0.2 / \mathrm{s}$ curve by $\sigma_{\max }(200 / \mathrm{s}) / \sigma_{\max }(0.2 / \mathrm{s})$, this is to say by $115 / 55$, gives the dotted line in Fig. 13. By comparison, direct integration of Eqs $(1,2)$ with material constants from Tables I and II for a 200/s strain rate gives the solid line in Fig. 13. These two predictions are clearly not in agreement and testing capabilities for strain rates up to 200/s are necessary. Among others, the so called split-Hopkinson method based on wave propagation analysis is a possible alternative, see [27].

The microstructure is also a source of uncertainty and bulk properties do not necessarily prevail in solder joints. Sizes are small and the traditional assumptions of scale independence, homogeneity and isotropy may not be applicable. Cooling rates are usually badly controlled within electronics which greatly affects the microstructure and introduces substantial scatter $[2,28]$. Subsequent phase coarsening at room and service temperature induces yield strength reduction (according to the Hall-Petch relation) and can lead to both softening and hardening, see [29] for a detailed review of annealing processes in $\mathrm{SnAgCu}$. 


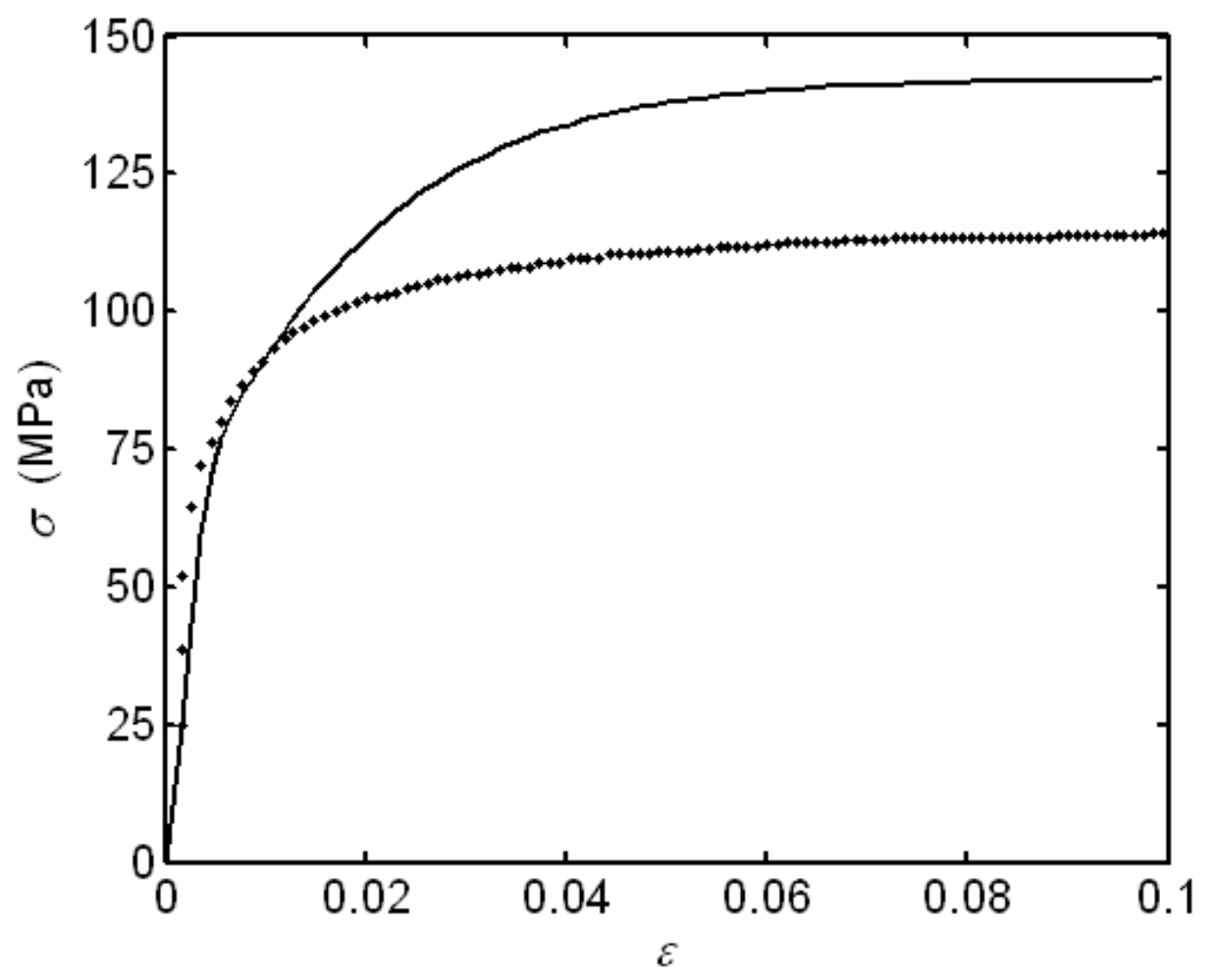

Figure 13: Comparison of an extrapolated experimental curve (dotted line) with the model prediction (solid line) for a strain rate of 200/s strain rate. The discrepancy shows the inability of the model to predict results outside the curve fitting range.

Solder joint cross sections before failure show a large presence of intermetallics at the junction between the copper pad and the bulk solder material, see scanning electron microscope images in Figs. (14a,15a). X-rays spectroscopy furthermore revealed these intermetallics to be $\mathrm{Cu}_{6} \mathrm{Sn}_{5}$ and $\mathrm{Cu}_{3} \mathrm{Sn}$ for $\mathrm{SnAgCu}$ and $(\mathrm{CuNi})_{6} \mathrm{Sn}_{5}$ for $\mathrm{SnAgCuNi}$.

Failure markedly differs for the two solder compositions: $\mathrm{SnAgCu}$ experiences brittle failure and cracks propagate between the copper pad and the intermetallics layer, see Fig. 14b whereas $\mathrm{SnAgCuNi}$ experiences ductile failure and cracks propagate between the intermetallics layer and the bulk solder material see Fig. 15b. As no intermetallics are modeled in the simulations, these effects are completely overlooked and certainly alter the outcome of the simulations. Thin films modeling and introduction of cohesive zones would be a way to take into account microstructure effects.

Finally it should be mentioned that drop test simulations are for obvious computational time reasons restricted to a single up and down bending of the PCB whereas in reality failures occur after several drops each consisting of several up and down bending. 


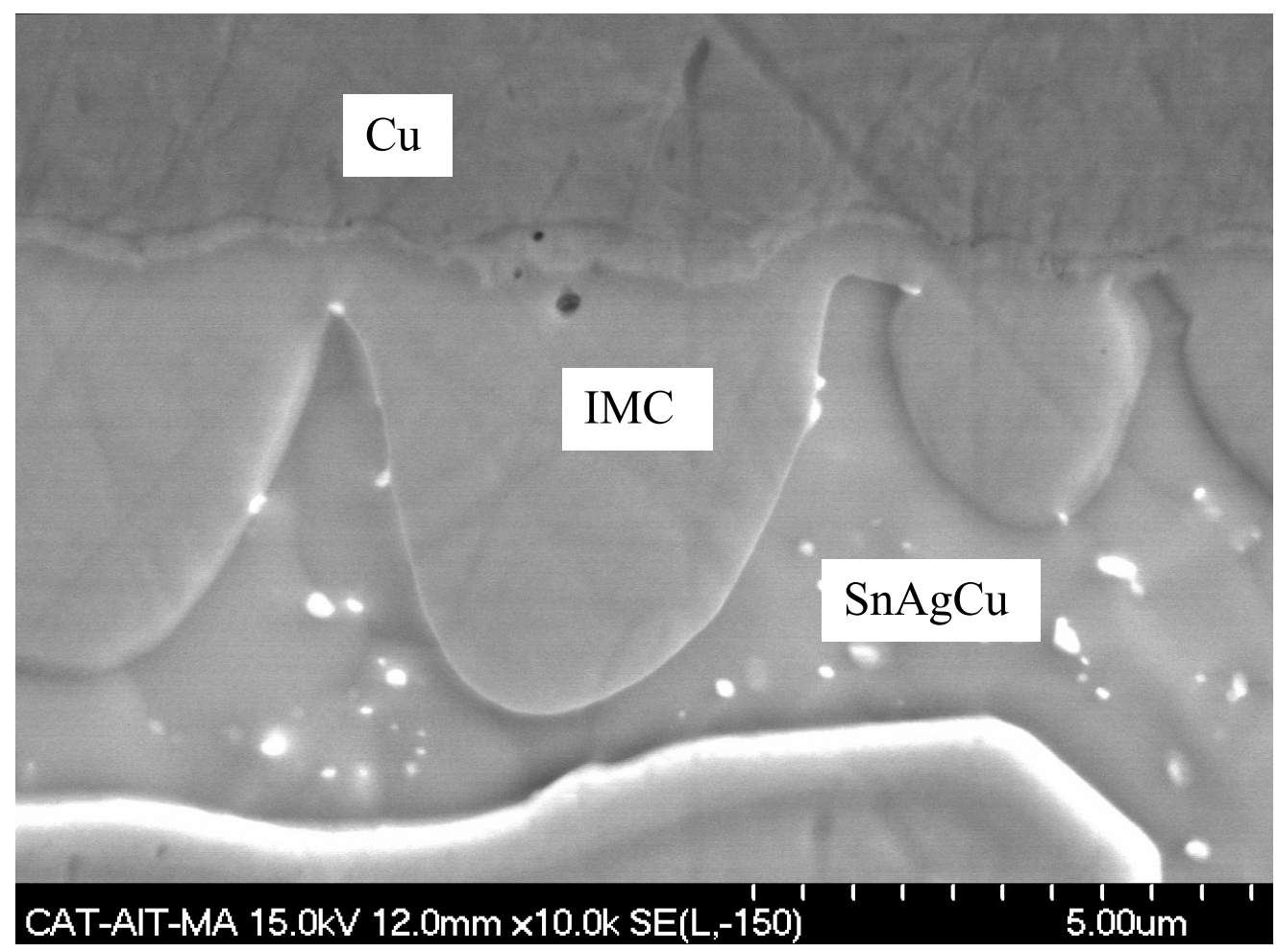

Figure 14a: Cross-section of $\mathrm{SnAgCu}$ solder on a $\mathrm{Cu}$ pad with intermetallics (IMC) in between.

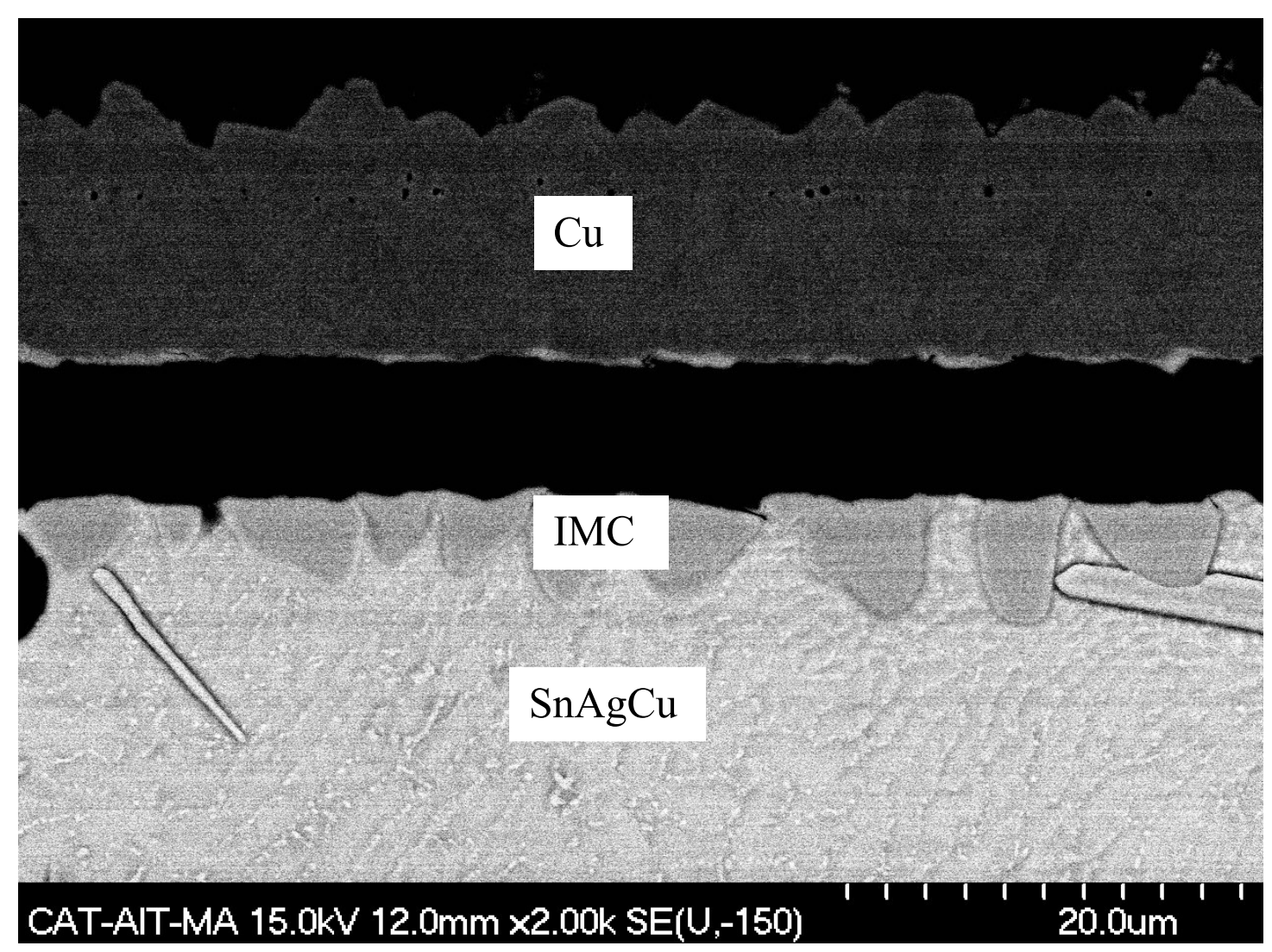

Figure 14b: Cracks in $\mathrm{SnAgCu}$ run between the $\mathrm{Cu}$ layer and the intermetallics (IMC). 


\section{$\mathrm{Cu}$}

CAT-AIT-MA $15.0 \mathrm{kV} 11.7 \mathrm{~mm} \times 10.0 \mathrm{k}$ SE(L,-150)

\section{$\mathrm{SnAgCuNi}$}

Figure 15a: Cross-section of $\mathrm{SnAgCuNi}$ solder on a $\mathrm{Cu}$ pad with intermetallics (IMC) in between.

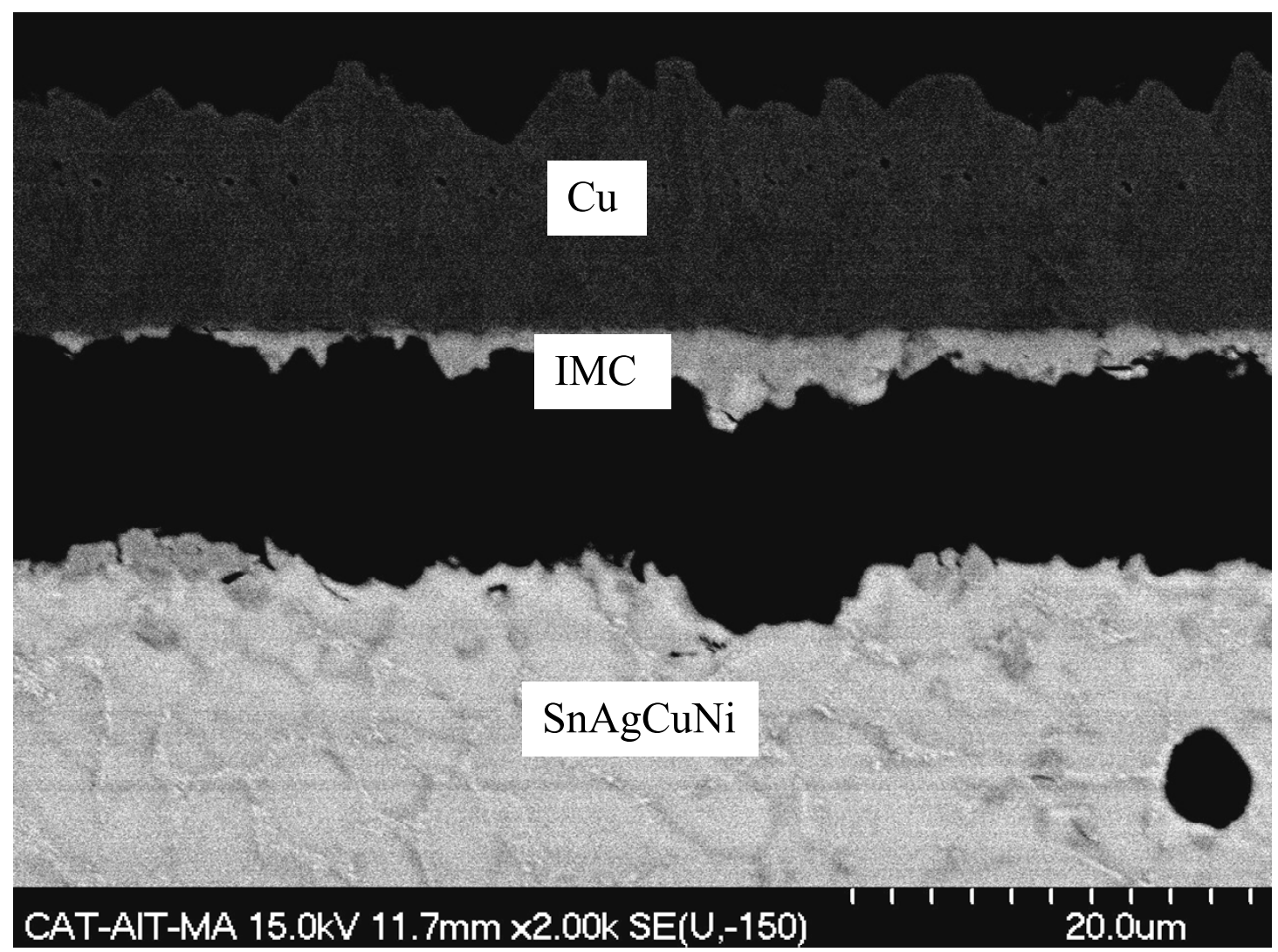

Figure 15b: Cracks in $\mathrm{SnAgCuNi}$ run between the intermetallics (IMC) and the solder material. 


\section{Conclusion}

Drop test simulation predictions are clearly not in agreement with drop test experiments. Criteria based on plastic strain or maximum peeling stress do not give the right failure outcome. With failure occurring at the vicinity of intermetallic compounds, microstructure must be taken into account much more thoroughly. Nevertheless, the material characterization presented here, even though only valid for relatively low strain rates, can still be used as the starting point for more advanced attempts to model solder joint bulk behavior.

\section{Acknowledgments}

This project was entirely funded by Infineon Technologies, Munich, Germany. Manager Heinz Pape is gratefully acknowledged for initiating the project and carefully following its evolution. Help and expertise from Dr. Jonas Faleskog, Hans Öberg and Christian Birzer within plasticity theory, material characterization and drop test experiments respectively were greatly appreciated. Special thanks to Matthias Hörmann at Cadfem for assistance with computer issues and LS-Dyna.

\section{Nomenclature}

$\begin{array}{lll}\varepsilon_{\mathrm{p}} & = & \text { plastic strain } \\ \left|\varepsilon_{\mathrm{p}}\right| & = & \text { effective plastic strain } \\ \dot{\varepsilon}_{0}, n & = & \text { viscoplastic parameters } \\ \sigma & = & \text { current stress } \\ \sigma_{y} & = & \text { current yield stress } \\ \sigma_{y_{0}} & = & \text { initial yield stress } \\ \sigma_{\infty} & = & \text { yield stress limit } \\ k & = & \text { hardening parameter (Perzyna model) } \\ h & = & \text { hardening parameter (Armstrong and Fredrick model) } \\ m & = & \text { mixed hardening parameter } \\ \alpha & = & \text { kinematic hardening function } \\ \alpha_{\infty} & = & \text { kinematic hardening limit } \\ K & = & \text { isotropic hardening function } \\ K_{\infty} & = & \text { isotropic hardening limit }\end{array}$

\section{References}

[1] Wang, G.Z., Cheng, Z.N., Becker, K., Wilde, J., 2001, "Applying Anand Model to represent the Viscoplastic Deformation Behavior of Solder Alloys," Journal of Electronic Packaging, vol. 123, pp. 247-253.

[2] Sarihan, V., 1993, "Temperature Dependent Viscoplastic Simulation of Controlled Collapse Solder Joint under Thermal Cycling," Journal of Electronic Packaging, vol. 115, pp. 16-21. 
[3] Wiese, S., Meusel, E., Wolter, K.-J., 2003, "Microstructural Dependence of Constitutive Properties of Eutectic SnAg and $\mathrm{SnAgCu}$ solders," 53 ${ }^{\text {rd }}$ Electronic Components and Technology Conference.

[4] Dube, M., Kundu, T., 2005, "Yield Function for Solder Elastoviscoplastic Modeling," Journal of Electronic Packaging, vol. 127, pp. 147-156.

[5] Anand, L., 1985, "Constitutive Equations for Hot-Working of Metals," International Journal of Plasticity, vol. 1, pp. 213-231.

[6] Brown, S.B., Kim, K.H., Anand, L., 1989, “An Internal Variable Constitutive Model for Hot Working of Metals," International Journal of Plasticity, vol. 5, pp. 95-130.

[7] Darveaux, R., 2000, "Effect of Simulation Methodology on Solder Joint Crack Growth Correlation," $50^{\text {th }}$ Electronic Components and Technology Conference.

[8] Busso, E.P., Kitano, M., Kumazawa, T., 1992, “A Visco-Plastic Constitutive Model for 60/40 Tin-Lead Solder Used in IC Package Joints," Journal of Engineering Materials and Technology, vol. 114, pp. 331-337.

[9] Armstrong, P.J., Fredrick, C.O., 1966, "A Mathematical Representation of the Multilinear Bauschinger Effect," C.E.G.B. Report, RD/B/N731.

[10] Busso, E.P., Kitano, M., Kumazawa, T., 1994, "Modeling Complex Inelastic Deformation Processes in IC Packages' Solder Joints," Journal of Electronic Packaging, vol. 116 , pp. 6-15

[11] Wei, Y., Chow, C.L., Lau, K.J. Vianco, P., Fang, H.E., 2004, "Behavior of Lead-Free Solder under Thermomechanical loading," Journal of Electronic Packaging, vol. 126, pp. 367-373.

[12] Basaran, C., Zhao, Y., Tang, H., Gomez, J., 2005, “A Damage-Mechanics-Based Constitutive Model for Solder Joints," Journal of Electronic Packaging, vol. 127, pp. 208214.

[13] Chaboche, J.L., 1986, "Time-Independent Constitutive Theories for Cyclic Plasticity," International Journal of Plasticity, vol. 2, pp. 149-188.

[14] Chaboche, J.L., 1989, "Constitutive Equations for Cyclic Plasticity and Cyclic Viscoplasticity," International Journal of Plasticity, vol. 5, pp. 247-302.

[15] White, C.S., Bronkhorst, C.A., Anand, L., 1990, “An Improved Isotropic-Kinematic Hardening Model for Moderate Deformation Metal Plasticity," Mechanics of Materials, vol. 10, pp. 127-147. 
[16] JEDEC Standard JESD22-B111, 2003, "Board Level Drop Test Method of Components for Handheld Electronic Products."

[17] Shetty, S., Lehtinen, V., Dasgupta, A., Halkola, V., Reinikainen, T., 2001, "Fatigue of Chip Scale Package Interconnects Due to Cyclic Bending," Journal of Electronic Packaging, vol. 123, pp. 302-308.

[18] Wong, E.H., Lim, K.M., Lee, N., Seah, S., Hoe, C., Wang, J., 2002 “Drop Impact test Mechanics and Physics of Failure," $4^{\text {th }}$ Electronics Packaging Technology Conference.

[19] Irving, S., Liu, Y., 2004, "Free Drop Test Simulation for Portable IC Package by Implicit Transient Dynamics FEM," 54 $4^{\text {th }}$ Electronic Components and Technology Conference.

[20] Wong, E.H., Mai, Y.-W., 2006, "New Insights into Board Level Drop Impact," Microelectronics Reliability, vol. 46, pp. 930-937.

[21] Luan, J.-E., Tee, T.Y., 2004, “Analytical and Numerical Analysis of Impact Pulse Parameters on Consistency of Drop Impact results," $6^{\text {th }}$ Electronics Packaging Technology Conference.

[22] Tee, T.Y., Luan, J.-E., Pek, E., Lim, C.T., Zhong, Z., 2004, “Advanced Experimental and Simulation Techniques for Analysis of Dynamic Responses during Drop Impact," $54^{\text {th }}$ Electronic Components and Technology Conference.

[23] Yeh, C.-L., Lai, Y.-S., 2004, “Transient Analysis of Board-level Drop Response of Leadfree Chip-scale Packages with Experimental Verifications," $6^{\text {th }}$ Electronics Packaging Technology Conference.

[24] Che, F.X., Pang, H.L., 2004, "Harsh Solder Joint Reliability Tests by Impact Drop and Highly Accelerated Life Test (HALT)," $6^{\text {th }}$ Electronics Packaging Technology Conference.

[25] LS-Dyna Keyword User's Manual, Livermore Software Technology Corporation, Version 970, 2003.

[26] Ansys Documentation Manuals, Ansys Inc., 2007.

[27] Gray, G., 2000, “Classic Split-Hopkinson Pressure Bar Testing,” American Society for Metals Handbook $12^{\text {th }}$ ed., vol. 8, pp. 462-476.

[28] Fix, A.R., López, G.A., Brauer, I., Nüchter, W., Mittemmeijer, E.J., 2004, "Microstructural Development of $\mathrm{SnAgCu}$ Solder Joints," Journal of Electronic Materials, vol. 34, pp. 137-142. 
[29] Xiao, Q., Bailey, H.J., Armstrong, W.D., 2004, "Aging Effects on Microstructure and Tensile Property of Sn3.9Ag0.6Cu Solder Alloy," Journal of Electronic Packaging, vol. 126, pp. 208-212.

\section{Appendix}

Details of the 3-D implementation are given here. The norm of a second order tensor is defined as $|\boldsymbol{M}|=\sqrt{\boldsymbol{M}: \boldsymbol{M}}=\sqrt{M_{i j} M_{i j}}$. The fourth order isotropic elasticity tensor is noted $\mathcal{L}$ and the fourth order identity elasticity tensor $\mathbf{I}$.

Quantities known at the beginning of the time-step:

- $\boldsymbol{\sigma}_{n}, \boldsymbol{\alpha}_{n}, K_{n}, \varepsilon_{\mathrm{p} n}^{\mathrm{eff}}$ (saved as internal variables)

- $\Delta \boldsymbol{\varepsilon}$ (calculated total strain increment over the step)

Trial stress tensor and deviatoric trial stress tensor:

$\boldsymbol{\sigma}_{*}=\boldsymbol{\sigma}_{n}+\mathcal{L} \Delta \boldsymbol{\varepsilon}$

$\boldsymbol{s}_{*}=\boldsymbol{\sigma}_{*}-\frac{1}{3} \operatorname{tr}\left(\boldsymbol{\sigma}_{*}\right) \mathbf{I}$

Reduced fully implicit stress tensor and reduced trial stress tensor:

$\xi_{n+1}=s_{n+1}-\alpha_{n+1}$

$\xi_{*}=\boldsymbol{s}_{*}-\boldsymbol{\alpha}_{n}$

Kinematic hardening tensor derivative and fully implicit increment of kinematic hardening tensor :

$\dot{\boldsymbol{\alpha}}=(1-m) h\left(\frac{2}{3} \dot{\boldsymbol{\varepsilon}}^{\mathrm{p}}-\frac{\boldsymbol{\alpha}}{\alpha_{\infty}} \dot{\boldsymbol{\varepsilon}}_{\mathrm{p}}^{\text {eff }}\right)$

$\Delta \boldsymbol{\alpha}=\frac{\alpha_{\infty}(1-m) h \Delta \lambda}{\alpha_{\infty}+(1-m) h \Delta \lambda}\left(\frac{\xi_{n+1}}{\xi_{n+1}^{\text {eff }}}-\frac{\boldsymbol{\alpha}_{n}}{\alpha_{\infty}}\right)$

where:

$\xi_{n+1}^{\text {eff }}=\sqrt{3 / 2}\left|\xi_{n+1}\right|$

Reduced fully implicit updated stress:

$\xi_{n+1}=\frac{\xi_{n+1}^{\text {eff }}}{\xi_{n+1}^{\text {eff }}+3 G \Delta \lambda+\frac{\alpha_{\infty}(1-m) h \Delta \lambda}{\alpha_{\infty}+(1-m) h \Delta \lambda}}\left(\xi^{*}+\frac{\alpha_{\infty}(1-m) h \Delta \lambda}{\alpha_{\infty}+(1-m) h \Delta \lambda} \frac{\boldsymbol{\alpha}_{n}}{\alpha_{\infty}}\right)$

Effective reduced fully implicit updated stress:

$\xi_{n+1}^{\mathrm{eff}}=\sqrt{3 / 2}\left|\left(\xi^{*}+\frac{\alpha_{\infty}(1-m) h \Delta \lambda}{\alpha_{\infty}+(1-m) h \Delta \lambda} \frac{\alpha_{n}}{\alpha_{\infty}}\right)\right|-\left(3 G \Delta \lambda+\frac{\alpha_{\infty}(1-m) h \Delta \lambda}{\alpha_{\infty}+(1-m) h \Delta \lambda}\right)$

Isotropic hardening derivative and fully implicit increment of isotropic hardening:

$\dot{K}=m h\left(1-\frac{K}{K_{\infty}}\right) \dot{\varepsilon}_{\mathrm{p}}^{\text {eff }}$

$\Delta K=\frac{m h\left(K_{\infty}-K_{n}\right) \Delta \lambda}{K_{\infty}+m h \Delta \lambda}$ 
Viscosity law:

$\Delta \lambda=\Delta t \dot{\varepsilon}_{0}\left(\frac{\xi_{n+1}^{\mathrm{eff}}}{\sigma_{\mathrm{y} 0}+K_{n}+\Delta K}-1\right)^{n}$

Insertion of (A5) and (A6b) into (A7) gives a scalar equation in $\Delta \lambda$.

Updates of the:

- effective reduced fully implicit updated stress $\xi_{n+1}^{\text {eff }}$ through (A5),

- reduced fully implicit updated stress $\xi_{n+1}$ through (A4).

Updates of the:

- kinematic hardening through (A3b) and $\boldsymbol{\alpha}_{n+1}=\boldsymbol{\alpha}_{n}+\Delta \boldsymbol{\alpha}$,

- isotropic hardening through (A6b) and $K_{n+1}=K_{n}+\Delta K$.

Update of the plastic strain increment:

$\Delta \boldsymbol{\varepsilon}^{\mathrm{p}}=\frac{3}{2} \frac{\xi_{n+1}}{\xi_{n+1}^{\text {eff }}} \Delta \lambda$

Update of the stress:

$\sigma_{n+1}=\sigma_{*}-\mathcal{L} \Delta \varepsilon^{\mathrm{p}}=\sigma_{*}-2 G \Delta \varepsilon^{\mathrm{p}}$ 